\title{
Sensorineural Deafness in Early Acquired Syphilis
}

\author{
Philippe Saltiel, Calvin A. Melmed, and David Portnoy
}

SUMMARY: A 36 year old male developed bilateral sensorineural deafness as the chief manifestation of secondary syphilis. Cerebrospinal fluid showed pleocytosis. Treatment with penicillin and prednisone resulted in good recovery of hearing. Initial recovery seemed dependent on corticosteroids. Deafness can complicate acquired syphilis in both early and late stages of the disease and may be its sole manifestation. Early acquired syphilitic deafness is usually the result of a meningitis affecting the eighth nerve and responds well to treatment. These features are contrasted with those of late acquired syphilitic deafness.

RÉSUMÉ: Un homme de 36 ans a présenté une surdité neurosensorielle bilatérale comme manifestation principale d'une syphilis secondaire. Le liquide céphalorachidien montra une hypercytose. Le traitement associant pénicilline et prednisone a amené une bonne récupération de l'ouie. Les stéroides ont semblé nécessaires initialement à l'amélioration. La surdité peut survenir comme complicaton d'une syphilis acquise à un stade précoce ou tardif de l'infection. Elle peut même en être l'unique manifestation. La surdité compliquant une syphilis à un stade précoce est généralement due à une méningite avec atteinte du nerf auditif et répond bien au traitement. Ce tableau est comparé à celui de la surdité d'une syphilis tardive.

Can. J. Neurol. Sci. 1983; 10:114-116

Sensorineural hearing loss can be a complication of both congenital and acquired syphilis (McNulty and Fasselt, 1981). In the latter, deafness may occur in both the early (secondary) and late (teritary) stages of the disease.

Early acquired syphilitic deafness usually reflects meningeal luetic infection (Vercoe, 1976) and unlike other forms of syphilitic deafness usually recovers with treatment (Becker, 1979; McNulty and Fasselt, 1981).

\section{Case Report}

A 36 year old homosexual male was admitted to hospital in September 1981 because of bilateral hearing loss. Six weeks before admission, he became aware of right-sided hearing loss and tinnitus. The hearing loss worsened progressively and ten days prior to admission, the other ear became involved.

Blood serology obtained three weeks after the onset of symptoms showed a Venereal Disease Research Laboratory (VDRL) titer of $1 / 64$, and positive fluorescent treponemal antibody absorption test (FTA-ABS) and Treponema pallidum hemaggutination assay (TPHA). Four days before admission he was treated with 2.4 million units of intramuscular benzathine penicillin $G$, following which he experienced fever, chills and myalgias interpreted as a Jarisch-Herxheimer reaction. An audiogram done at that time showed a moderately severe bilateral sensorineural hearing loss. Betamethasone $1 \mathrm{mg}$ orally, three times daily, was prescribed and the patient was admitted to hospital.

There was no headache or fever. The patient denied having had a chancre but recalled a mottled skin rash over the trunk, of two weeks duration which had resolved when his hearing loss began. There was a history of exposure to syphilis in September 1979. Blood VDRLs prior to 1979 had been negative. In December 1979, despite a negative VDRL, he received IM benzathine penicillin $\mathrm{G} 2.4$ million units.

On physical examination, no mucocutaneous lesion or lymphadenopathy were noted and the only abnormality was bilateral decreased hearing. The Weber and Rinne tests were normal and compatible with a sensorineural type of hearing loss.

A lumbar puncture showed a normal opening pressure, 7 red blood cells and 24 lymphocytes per $\mathrm{mm}^{3}$; protein $46 \mathrm{mg} \%$, glucose $54 \mathrm{mg} \%$ (blood glucose $90 \mathrm{mg} \%$ ); cerebrospinal fluid (CSF) VDRL and FTAABS negative; cultures for bacteria, acid fast bacilli, fungi and CSF cytology were all negative.
The patient was treated with aqueous penicillin $G 21$ million units intravenously daily in six divided doses for 3 weeks, and prednisone $40 \mathrm{mg}$ daily which was tapered and stopped after $2 \frac{1}{2}$ weeks. His hearing improved, but shortly after the corticosteroids were stopped and while still on penicillin, it deteriorated again. An audiogram showed a $5 \mathrm{~dB}$ loss, contrasting to the steady improvement on previous audiograms. Prednisone $20 \mathrm{mg}$ daily was reinstituted and hearing again improved, and in 11 weeks the audiogram was within the normal range. Corticosteroids were discontinued after a further 11 weeks with no recurrence of deafness.

Nine weeks after the beginning of treatment, the blood VDRL titer had fallen to $1 / 16$, while the FTA-ABS and TPHA remained positive. The CSF showed 4 red blood cells and 16 lymphocytes per $\mathrm{mm}^{3}$. The protein was $28 \mathrm{mg} \%$. Five months after treatment the blood VDRL titer had fallen further to $1 / 4$, with FTA-ABS positive and TPHA negative. CSF reexamination revealed 10 lymphocytes per $\mathrm{mm}^{3}$. The protein was 34 $\mathrm{mg} \%$.

\section{DISCUSSION}

There are few reports of deafness in early acquired syphilis. Vercoe (1976) was able to find 11 cases (including 1 of his own) from the beginning of the penicillin era up to 1976. Since then 3 additional cases have been reported (Balkany and Dans, 1978; Von Schulthess, 1978). The hearing loss usually has a sudden onset, is rapidly progressive and tends to be bilateral with minimal vestibular symptoms (Vercoe, 1976; McNulty and Fasselt, 1981). Often there is no history of primary syphilitic infection and the systemic manifestations of secondary syphilis (rash, mucous patches, lymphadenopathy) may be minimal or absent (Willox and Goodwin, 1971; Vercoe, 1976; Balkany and Dans, 1978). Serological testing is required to distinguish this entity from other causes of sudden neural deafness.

In our patient, as in the majority of similar cases reported in the literature, there was evidence of CSF infection.

In early syphilis, spirochetal invasion of the subarachnoid

From the Division of Neurology, Montreal General Hospital and McGill University, Montreal, Canada.

Received September 30, 1982. Accepted for publication January 31, 1983.

Reprint requests to: Dr. Calvin A. Melmed, Division of Neurology, Montreal General Hospital, 1650 Cedar Avenue, Montreal, Quebec,

Canada H3G 1 A4. 
space is common. The perilymph is in communication with the CSF space via the cochlear aqueduct. While only $1-2 \%$ of patients with early syphilis develop clinical symptoms due to meningitis (Stokes et al., 1944), 5\% or more have abnormal spinal fluid examinations (pleocytosis, elevated protein) (Bauer et al., 1952). Even among those patients with normal spinal fluid, spirochetes can be recovered in 15$40 \%$ of cases by inoculation of the CSF into rabbits (Stokes et al., 1944).

The deafness complicating early acquired syphilis is the result of a basilar meningitis affecting the eighth nerve, particularly the auditory branch (Vercoe, 1976). Deafness may be the only manifestation of the basilar meningitis as in our patient, or may be associated with headache, stiff neck, other cranial nerve palsies, optic neuritis and even hemiparesis and dysphasia (Merritt and Moore, 1935; Nelson and Duncan, 1945; Loch and Tucker, 1948; Wetherill et al., 1965; Balkany and Dans, 1978). The CSF in these cases characteristically shows pleocytosis and elevated protein with or without positive VDRL.

There are a few reported cases of deafness or vertigo complicating early acquired syphilis in which the CSF was normal, possibly because spirochetal invasion of the perilymph resulted in inflammation confined to the labyrinth and cochlea (Vercoe, 1976; Von Schulthess, 1978).

In contrast, in late acquired syphilitic deafness, the CSF is usually normal (Moore, 1947; Becker, 1979). Temporal bone osteitis results in secondary degeneration of the cochlear end-organ (Goodhill, 1939; Becker, 1979). Occasionally, cases of deafness complicating late acquired syphilis have evidence of CSF infection, reflecting a different pathogenesis. Figure 1 provides a summary of the various pathologic mechanisms of deafness and their associated CSF findings in early and late acquired syphilis.

The treatment of deafness in early acquired syphilis usually results in good recovery in hearing (Moore, 1947; Von Schulthess, 1978; Becker, 1979; McNulty and Fasselt, 1981). The optimal penicillin regimen remains uncertain (McNulty and Fasselt, 1981). Since deafness in early acquired syphilis appears secondary to CSF infection, high dose intravenous penicillin has been recommended, but some cases (Nelson and Duncan, 1945; Loch and Tucker, 1948; Alergant, 1965; Willcox and Goodwin, 1971; Vercoe, 1976) have recovered completely on penicillin regimens which would not be expected to produce treponimicidal CSF levels. CSF pencillin levels have never been reported in these patients.

In congenital or late acquired syphilitic hearing loss, the combination of steroids and penicillin appears superior to the use of penicillin alone (Becker, 1979; Zoller et al., 1979). The value of steroids in early acquired syphilitic deafness is uncertain. Complete recovery of hearing has occurred with penicillin therapy alone in some cases (Nelson and Duncan, 1945; Loche and Tucker, 1948; Balkany and Dans, 1978), but several authors advocate a short course of steroids prior to penicillin therapy to avoid the Jarish-Herxheimer reaction which may result in increased deafness or vertigo (Will-

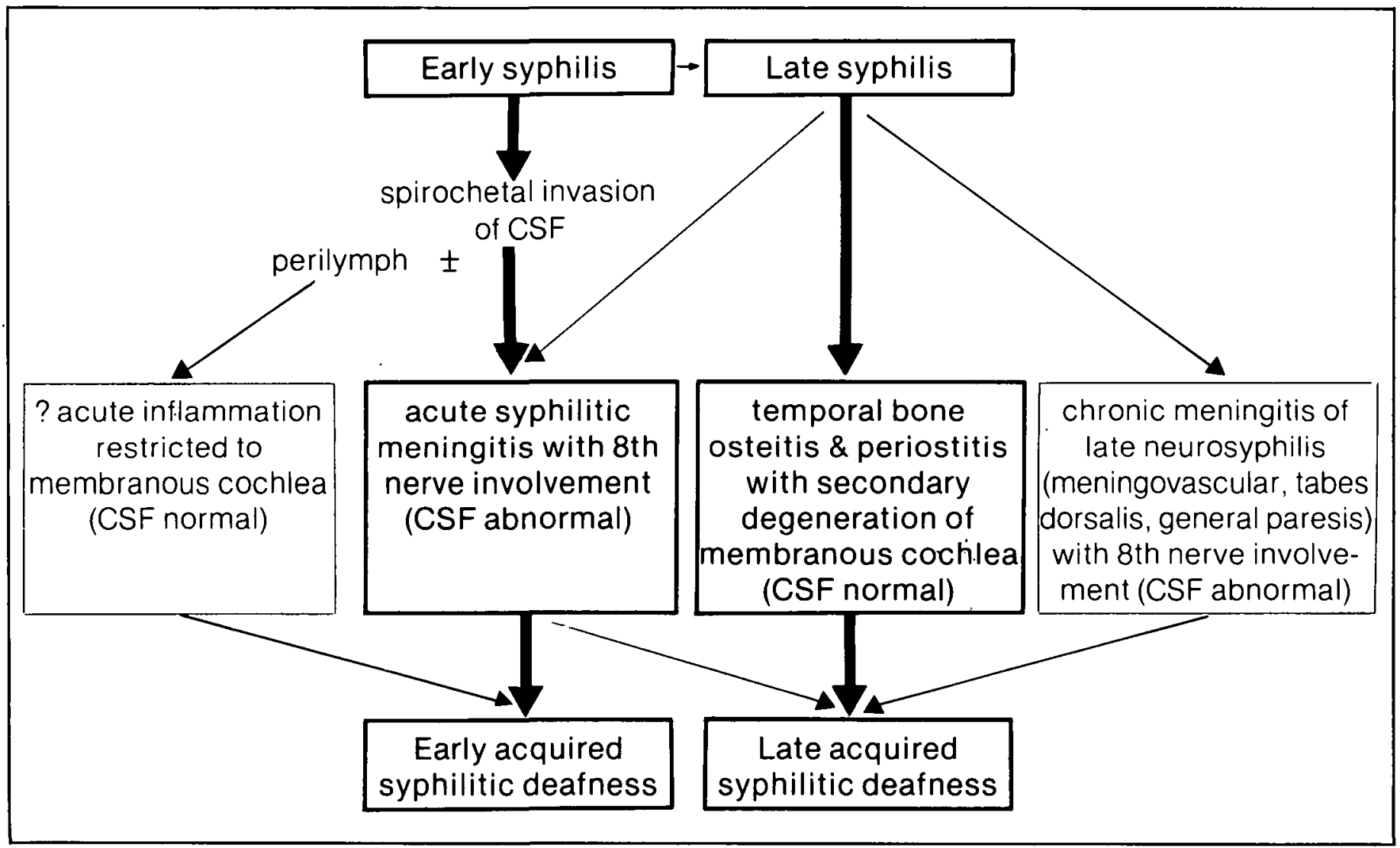

Figure 1 - Pathologic mechanisms of deafness and their associated CSF findings in early and late acquired syphilis. 
cox and Goodwin, 1971; Vercoe, 1976). In our patient, hearing recovery was steroid dependent initially. A similar phenomenon has been described previously in one patient where control of the tinnitus fluctuated with the dose of steroids (Vercoe, 1976).

Despite the various forms of treatment, the majority of patients with early acquired syphilitic deafness have had excellent recovery in hearing and vestibular function (Nelson and Duncan, 1945; Loche and Tucker, 1948; Willcox and Goodwin, 1971; Vercoe, 1976). It has been suggested that those who do not improve have had infarction of the 8th cranial nerve complicating the meningitis (Merritt and Moore, 1935).

In summary, hearing loss may be the presenting manifestation of early acquired (secondary) syphilis. This diagnosis requires a high index of suspicion. With prompt treatment there is a good prognosis for recovery.

\section{References}

Alergant, C.D. (1965). Eighth nerve deafness in early syphilis. Brit. J. Vener. Dis. $41: 300-301$
Balkany, T.J., Dans, P.E. (1978). Reversible sudden deafness in early acquired syphilis. Arch. Otol. 104: 66-68.

Bauer, T.J., Price, E.V., Cutler, J.C. (1952). Spinal fluid examinations among patients with primary or secondary syphilis. Amer. J. Syph. 36: 309-318.

Becker, G.D. (1979). Late syphilitic hearing loss: a diagnostic and therapeutic dilemma. Laryngoscope 89: 1273-1288.

Goodhill, V. (1939). Syphilis of the ear: a histopathologic study. Ann. Otol. Rhinol. Laryngol. 48: 676-706.

Loche, W.E., Tucker, H.A. (1948). Penicillin treatment of nerve deafness due to syphilis. Ann. Otol. Rhinol, Laryngol. 57: 167-180.

McNulty, J.S., Fasselt, R.L. (1981). Syphilis: an otolaryngologic perspective. Laryngoscope 91 : 889-905.

Merritt, H.H., Moore, M. (1935). Acute syphilitic meningitis. Medicine 14: 119 183.

Moore, J.E. (1947). Penicillin and syphilis. Blackwell, Oxford. p. 265-270.

Nelson, R.A., Duncan, L. (1945). Acute syphilitic meningitis treated with penicillin. American Journal of Syphilis, Gonorrhea, and Venereal Diseases 29: 141. 163.

Stokes, J.H., Beerman, H., Ingraham, N.R. (1944). Modern clinical syphilology. 3rd ed. Saunders, Philadelphia. p. 605-615.

Vercoe, G.S. (1976). The effect of early syphilis on the inner ear and auditory nerves. J. Laryng. Otol. 853-861.

Von Schulthess, G. (1978). Kasuistischer Beitrag zur luetischen Gehörsstörung. HNO 26: 374-376.

Wetherill, J.H., Webb, H.E., Catterall, R.D. (1965). Syphilis presenting as an acute neurological illness. Brit. Med. J. 1: 1157-1158.

Willcox, R.R., Goodwin, P.G. (1971). Nerve deafness in early syphilis. Brit. J. Vener. Dis. 47: 401-4-6. 